\title{
The application of impact counseling in therapy started with individual counseling expressive to cope with the personal problems by college students
}

\author{
Syahniar \\ Universitas Negeri Padang \\ ${ }^{*}$ Corresponding author, ఏe-mail: Syahniar9@gmail.com
}

\begin{abstract}
Various approaches and theory can be applied to help students to cope with personal problems; one approach that can be applied is the impact counseling. Impact Therapy is a teaching process that carried out by the counselor, where a counselor wrote and visualized to clients about what the client wants, the client will do, how clients assess their behavior and how clients to plan what to do next. This is illustrated by Ed Jacobs As WDEP (Want, Doing, Evaluate, and Plan). Before using the impact counseling for students who are not able to communicate the problems that they experienced first counselor implemented expressive therapy. Expressive therapy known as a therapy in counseling and psychotherapy in which the client can communicate and express its feelings and their thoughts through activities related to art, music, dance, drama, poetry, as well as games. Expressive therapy is also called the "Creative Arts Therapy". Especially art, music, drama and poetry.
\end{abstract}

Keywords: Impact of Counseling, Expressive Therapy

How to Cite: Syahniar. (2017). The application of impact counseling in therapy started with individual counseling expressive to cope the personal problems by college students. Couns-Edu: International Journal of Counseling and Education, 2(2): pp. 63-69. DOI: https://doi.org/10.23916/002017027420

\section{Introduction}

Students are a group of young people who are studying in college. Activities and tasks the student as a learner is learning the science, organizational, community and learning to be a leader to achieve success in life. Students are often referred to as a group of scholars and intellectuals who hold a heavy burden on the shoulders of determining the fate of the nation's future (Ishaq, 2006).

Students with higher capacity are expected to understand the concept, can be mapped the problem and choosing the best solution for these problems (Dweck, 2007; Swales \& Feak, 2004). However, various problems may arise during the implementation of a student in academic activities, the number of activities to be undertaken and implemented, many demands which must be met, which not good time management, and project work are piling up (Collier \& Morgan, 2008; Graunke \& Woosley, 2005). Such conditions according to Sarafino predicted to be stressful on the student when he was not able to meet these demands (Sarafino, 2006). 
The problems experienced by students, Sometimes there are students who are easily communicating the problems they are experiencing (Hansen \& Liu, 2005; Stiggins, Arter, Chappuis, \& Chappuis, 2004), both to friends and faculty academic adviser (PA). However otherwise, there are students who are unable to communicate the problem that happened with other people. Therefore, as the PA responsible lecturers on campus need to take reasonable steps to help students from both groups and individuals so that they are free from the problems experienced.

Various approaches and theory can be applied to help students overcome personal problem, one approach that can be applied is the impact of counseling (Khotijah \& Rahman, 2017). Impact Therapy is a teaching process carried out by the counselor, where a counselor wrote and visualizes to clients about what the client wants, the client will do, how clients assess their behavior and how clients to plan what to do next. This is illustrated As WDEP (Want, Doing, Evaluate, and Plan) by Jacobs et.al (E. E. Jacobs, Masson, Harvill, \& Schimmel, 2011).

Before using, the impact of counseling for students who are not able to communicate the problems, they experienced first implemented expressive therapy. Expressive therapy known as a therapy in counseling and psychotherapy in which the client can communicate and express its feelings and their thoughts through activities related to art, music, dance, drama, poetry, as well as games(Andrusyna, Luborsky, Pham, \& Tang, 2006; Klorer, 2005). Expressive therapy is also called the "Creative Arts Therapy" with specially art, music, drama and poetry (Atkins, et al., 2011; Malchiodi, 2014).

\section{Problems}

From the background that mentioned above, several issues need to be addressed as; (1) How is understanding the impact of counseling, (2) How can understand therapeutic expressive, (3) Application of Impact Counseling in individual with Expressive Therapy that begins with disclose personal experienced by students.

\section{Discussion}

\section{Definition of Impact Counseling}

Impact counseling is a creative approach to counseling that is initiated by Ed Jacobs. $\mathrm{PhD}$ from West Virginia University. A counselor in the counseling process must be creative in selecting and using effective techniques to help clients(Hayes, 2008; McAuliffe \& Eriksen, 2000). A counselor should be able to convince clients with a variety of creative techniques(Rubin, 2016) so that the client does not get tired to follow the counseling process. In the impact therapy, the theory of creative is needed, such as the use on the theory of creative, taking into account the time, teaching, practice and thinking, which is packed with the term 5 "T" (Theory, Timing, Teaching, Training, and Thinking (E. Jacobs, 2011).

Furthermore Impact Therapy using a variety of creative approaches in counseling such as REBT (rational emotive behavior therapy), TA (Transactional analysis), Reality therapy, and Gestalt (E. Jacobs, 2011).

A counselor will approach impact therapy should be capable and seek to use all the senses in counseling, able to raise the motivation of the client, convince the client, and make the counseling process to be interesting and effective so that clients gain real advantages in the counseling process, and the client is willing make changes that need to be done, should be able to formulate the road and the steps to be performed by the client. In this case, Ed Jacobs packaging 4 "M" in counseling. Namely: Multi-sensory, motivational, Marketing, and Maps(E. Jacobs, 2011).

The results from the counseling process are the change for the client. To the occurrence of a change for the client needs to do the following steps.

a. Pre contemplation: when a client comes counselor thinks the client is in a state of how, at this stage the client has not thought to the changes that will they do.

b. Contemplation: at this stage, the counselor began designing interventions, and clients start thinking about changes.

c. Preparation: the client began to prepare for change.

d. Action: client started doing and makes changes.

e. Maintenance: run changes 


\section{f. Termination: change (Norcross, Krebs, \& Prochaska, 2011)}

Impact Therapy as a creative technique in counseling therapy also uses the reality that mentions five individual needs: the need for: a sense of belonging, power or ability, pleasure, freedom or lack of dependence, survival (E. Jacobs, 2011).

Impact Therapy is also a learning process carried out by the counselor, where a counselor wrote and visualizes to clients about what the client wants, the client will do, how clients assess their behavior and how clients to plan what to do next. This is illustrated As WDEP (Want, Doing, Evaluate, and Plan) by Ed Jacob(E. Jacobs, 2011).

Other approaches are also used in impact therapy is REBT (Rational Emotive Behavior Therapy), which holds that thought which causes feelings. Someone felt something according to what he was thinking. In the theory of REBT using the ABC approach in assisting clients, and these can be written on a blackboard counselor as follows:

a. The situation or person or event Sample; Clients shoplifting at the mall

b. The beliefs or self-talk. Example; I have embarrassed the family

c. Feelings and behavior. Example; I feel guilty

Counselors replace with the words: I've made a mistake.

Counselor: What did you during the span of your life is to do well?

Most people assume that "A" is that the cause of the "C. "Counselor REBT acknowledges that" B "is the cause of the" C ". Therefore, in the counseling process "B" needs to be changed.

In man, there is no rational belief and irrational belief. The counselor's task to replace the irrational belief that exists on the client becomes a rational belief. Some irrational beliefs that exists within an individual are as follows:

a. Absolute individual loved by people who are important in their environment.

b. Absolute everyone must be perfect and can reach achievements in all fields.

c. There are some people poor, weak, helpless, these people should be punished and ostracized.

d. It is very disappointing and a catastrophe if there is something that goes wrong.

e. Unhappiness is something that is beyond the control over the individual.

f. If there is something dangerous, then the individual should think about.

g. It is easy to run away from the difficulties and responsibilities than to face it.

h. Individuals need to depend on others.

i. Genesis of the past determines the future now.

j. A person must feel unhappy with the problems of others.

$\mathrm{k}$. To answer a problem, there must be the most appropriate way and the most correct.

Further impact therapy also uses Transactional Analysis approach, using ego grams comprising: Critical Parent (Self / Other), adult, child Free, Not Ok Child. In addition, it also uses the empty chair technique, using pictures. With this approach, the counselor helps the client to understand the conflicts with others.

Of the various opinions on the above, it can be concluded that the Impact counseling is a creative technique in counseling, which requires the counselor to be able to use a variety of creative techniques in counseling. Counselors use a variety of media, tools that can motivate the client to make changes. The counselor should be able to convince the client so that the client does not feel bored and seek to undergo a counseling process effectively. Various creative approaches have been used in Impact Therapy as REBT, Reality Therapy, TA, and gestalt.

\section{Definition Therapy Expressive}

Expressive therapy known as a therapy in counseling and psychotherapy in which the client can communicate and express its feelings and their thoughts through activities related to art, music, dance, drama, poetry, as well as games(Brodley, 2002; Estrella, 2005). Expressive therapy is also called the "Creative Arts Therapy" Especially art, music, drama and poetry (Atkins, et al., 2011; Malchiodi, 2014).

Furthermore, expressive therapy is a form of therapy used in psychotherapy and counseling that aims to channel the emotions and thoughts of individuals, reducing stress and conflict, through the medium of drama, making pictures and music(Klorer, 2005; Malchiodi, 2012). 
Of the various opinions that have been described can be concluded that the therapy expressive is a form of therapy that can be used by counselors to help clients uncover and communicate the feelings, thoughts through media and events related with the activities of art, dance, drama, poetry, and the form of the game.

\section{Therapeutic Role in Providing Assistance Expressive}

In general, both in counseling and psychotherapy, expressive therapy can be done either individually, family, or as a group(Classen, et al., 2001). A counselor expressive first explains the meaning, using different forms of games, music, poetry, stories and so on. Depending on the client, the therapist uses closure activities with games, movement, storytelling, etc. relaxation. In the implementation of expressive therapy may use one or more models expressive therapies such as drama, then there is a game or a poetry reading, and so on.

\section{Characteristics of Unique Therapy Expressive}

Expressive therapy is a therapy that has a uniqueness that is used in counseling and psychotherapy as it has some special characteristics(Malchiodi, 2013). Uniqueness expressive therapy can be limited in the following areas.

\section{a. Expression or self.}

All therapies expressive, aims to develop individual self-exploration. Expressive therapy not only develops self-exploration but in every episode of treatment also develop how the client can communicate what feels, and it occurred within the client (Molina, Monteiro-Leitner, Garrett, \& Gladding, 2005). Fundamentally, counselor and client work together to express themselves in the form express feelings, perceptions, develop self-understanding.

b. Active participation

Expressive therapy is known in psychology as "action therapies" (Wiener, 1999) because the action-oriented method used, where the client actively explore themselves and communicate ideas and feelings through the medium of music, drama, movement and dance, games and so on.

c. Imagination

Levinne suggested that the imagination was the basis used expressive therapy in art activities and games(Levine, 1999). Imagination is essential and fundamental in the overall expressive therapy(McNiff, 2008).

The linkage and relationship between physical body and thinking, National Center for Complementary and Alternative Medicine (NCCAM) in 2004 revealed that the relationship between the physical body at the thought. The ability to think physically affects the functions within the body (Barnes, Powell-Griner, McFann, \& Nahin, 2004).

\section{Restrictions Therapy Expressive}

Limitation expressive therapy in relief can be applied to all ages, groups, and individuals who are psychologically disturbed.

Application of Impact Counseling Individual with Expressive Therapy Begins to Help Reveal and Cope Personal Problems Suffered Students.

The steps that can be done are as follows:

a. The first step to implement expressive therapy to a student who becomes a child care PA. To the students was asked to choose any equipment provided lecturers, including equipment owned by students.

b. Students are given the time to choose the equipment according to her condition during approximately 10 minutes. Afterwards, the students are asked to express and tell what is felt, experienced, contemplated and the problems experienced by the equipment chosen. Students gradually and spontaneously communicate the feelings they experienced as follows.

c. Students with the name (pseudonym), feeling depressed and embarrassed to be on campus because they felt the campus environment perceive her as a woman who is not good. These circumstances make orchids become lazy to come to campus and do not want to finish the proposal. While parents and family is always asked when they graduate to remember orchids now are at half to ten. 
d. The next step lecturer PA resume activities in the implementation of impact of counseling in individual counseling. Impact Therapy as a creative technique in counseling therapy also uses the reality with five individual needs: the need for: a sense of belonging, power or ability, pleasure, freedom or lack of dependence, survival (Ed Jacobs, 2011).

Impact Therapy is also a learning process carried out by the counselor, where a counselor wrote and visualizes to clients about what the client wants, the client will do, how clients assess their behavior and how clients to plan what to do next. This is illustrated by Ed Jacobs (2011) As WDEP (Want, Doing, Evaluate, and Plan).

$\mathrm{W}=$ Wants. Clients will give meaning to their needs, desires, perceptions, perceptions and his hope to counselors and of themselves. Clients analyze every aspect to the life she wanted. To be able to perform activities of meaning needs, the counselor must perform intelligent actions through a variety of basic questions, such as: If you are the person you want, you will be what kind of person? Will be what your family if you and your family desire for each other? What do you do if you live the way you want? Do you really want to change your life? What you want that you probably will not get out of this life? What made you stop from making the changes you want?

$\mathrm{W}$ : not only related to the needs but also the perception. Although not exactly the same situation with the lives of children in the West, but there is a similar thought in which the locus of control is perceived as a source of needs. If in the West, there is a belief that external locus of control is closely related to behavior that is not effective, cannot necessarily be said is equal to the culture of Indonesia. The majority of our life is precisely controlled by external. So one goal of counseling is to help clients perceive the reality of inner control and direct her to change their behavior, although it cannot be released by the sizes of the external clients, especially those who are mean.

$\mathrm{D}=$ Direction or Doing. This phase emphasizes the behavior is the moment, the focus to gain awareness and change behavior during this time, do not focus on the client's feelings. Early counseling begins by discussing the purpose of the client's life. Ask the client: what they do during this, and if they do it toward fulfilling their needs? "Where is the last option you take?" "What is there in the mind you are now towards what your last wish to be fulfilled within one month, one year, two years hanceforth?" "Would you describe the direction your behavior without making considerations?"There are common questions that are used to try to help clients improve their awareness of their choices that look like from a distance. Through describing their overall goal, the client becomes ready to evaluate and change the thoughts and behaviors.

$\mathrm{E}=$ Evaluation. Evaluation involves consideration of the client in the direction behaviors, actions, desires, perceptions, new directions, and specific plans Wubbolding. The task of the counselor is to ask the client to evaluate the quality of their actions and help them make effective choices(Triyono, 2016 ).

E: ask the client to produce a self-evaluation. Glasser in (Triyono, 2016 ) describes the self-evaluation as the core of counseling reality. Furthermore, an important milestone in environmental counseling procedure. That is, the evaluation is the handle of the elements of other phases, if the evaluation is not a good road, then counseling will not run well(Wubbolding, 2013).

$\mathrm{P}=$ Planning. When clients determine what they want to change, they are generally prepared to explore the possibility of other behaviors and formulate a new action plan that is more rational and realistic. The process of creating and implementing a plan allows people to begin to gain effective control over effective at their lives. There must be a commitment to the implementation is.

P: ask clients to make a plan of action to meet their needs more effectively. When clients make a plan and follow through, they took over their lives by directing their energy into a single point of new measures implemented. The counselor facilitates the preparation of a plan to teach clients that plan that managed to have several characteristics. The plan must have the characteristics SAMIC: Simple (Simple), Attainable (achievable), Measurable (measurable), Immediate (short-term), and Committed to (commit to). For example, a new behavior plan is not enough to say to establish good relationships with peers. This statement is not immediately enforceable. He still needs to be operational, for example, by saying greet comrades in every encounter. Expressions greeting "Hi", "Hello", "Good Morning", Assalamu'alaikum ", or" Assalamu'alaikumwarahmah "and so is the behavior of a simple, God willing can be achieved, can be measured by observing, did not take long, and the latter actually commit done by the client. Other 
concrete examples from the behavior of a good relationship are responding with full attention to the story comrades talk. Can be taught to clients attending behaviors (facial expressions, gestures, nods head).

Table 1 Implementation concept WDEP

\begin{tabular}{|c|c|c|}
\hline & Process & Applied \\
\hline W & What do you want this time? & -I Want my thesis done faster, and anxious to graduate. \\
\hline D & $\begin{array}{l}\text { What are you doing right } \\
\text { now? }\end{array}$ & $\begin{array}{l}\text {-Not Want to come to campus } \\
\text {-Not Want to meet the lecturers } \\
\text {-Not Want to write a research proposal } \\
\text {-Feeling that friends have a negative perception about myself } \\
\text {-Feeling that supervisor negatively perceive myself } \\
\text {-Feeling ashamed to come to campus }\end{array}$ \\
\hline $\mathrm{E}$ & $\begin{array}{l}\text { What you are doing can } \\
\text { achieve anything you want? }\end{array}$ & -I Guess what I'm doing so far could not achieve what I want. \\
\hline $\mathrm{P}$ & $\begin{array}{l}\text { Let us stay on track to get } \\
\text { what you want. }\end{array}$ & $\begin{array}{l}\text { A plan that would do is a form of: } \\
\text { 1. I will try to convince myself that I had to come to campus. } \\
\text { 2. I'd braced myself and changed my perception that my } \\
\text { supervisor is a good person and willing to guide my thesis, } \\
\text { although lecturers scold me, would I accept it with pleasure and } \\
\text { positive. } \\
\text { 3. I will try to motivate myself to go into the library and started } \\
\text { looking for materials to write my proposal. } \\
\text { 4. I try to change my negative perception about my friend, and I } \\
\text { will always think positive behavior towards all my friends against } \\
\text { me, I try to always smile to my friends. } \\
\text { 5. I try to change my perception of my supervisor, I will try to } \\
\text { meet him and apologize. Whatever the reaction given by the } \\
\text { supervisor I will always I receive with positive thoughts. } \\
\text { 6. I tried to made perception with positive campus environment } \\
\text { so that I feel happy and not ashamed anymore to come to } \\
\text { campus. }\end{array}$ \\
\hline
\end{tabular}

\section{Conclusions}

Expressive therapy can be explored and reduce the problem of client. can be concluded that the Impact counseling is a creative technique in counseling, which requires the counselor to be able to use a variety of creative techniques in counseling. Counselors use a variety of media, tools that can motivate the client to make changes. The counselor should be able to convince the client so that the client does not feel bored and seek to undergo a counseling process effectively. Various creative approaches have been used in Impact Therapy as REBT, Reality Therapy, TA, and gestalt. This approach recommended using for counselor and especially school counselor.

\section{Acknowledgments}

Thanks to leader, dean and colleagues in the guidance and counseling department faculty of education Universitas Negeri Padang. The manuscript was presented at the 2nd International Seminar on Education, Rocky Hotel Convention Center Padang, in the faculty of education Universitas Negeri Padang with Intitut Pendidikan Guru Kampus Pendidikan Teknik Malaysia. 


\section{Reference}

Andrusyna, T. P., Luborsky, L., Pham, T., \& Tang, T. Z. (2006). The mechanisms of sudden gains in supportive-expressive therapy for depression. Psychotherapy Research, 16(5), 526-536.

Atkins, S., Knill, P. J., Simoneaux, G., Abbs, K., Kalmanowitz, D. L., Huss, E., et al. (2011). Art in action: Expressive arts therapy and social change: Jessica Kingsley Publishers.

Barnes, P. M., Powell-Griner, E., McFann, K., \& Nahin, R. L. (2004). Complementary and alternative medicine use among adults: United States, 2002. Paper presented at the Seminars in integrative medicine.

Brodley, B. T. (2002). Client-centered: An expressive therapy. The Person-Centered Journal, 9(1), 59-70.

Classen, C., Butler, L. D., Koopman, C., Miller, E., DiMiceli, S., Giese-Davis, J., et al. (2001). Supportive-expressive group therapy and distress in patients with metastatic breast cancer: a randomized clinical intervention trial. Archives of general psychiatry, 58(5), 494-501.

Collier, P. J., \& Morgan, D. L. (2008). "Is that paper really due today?": differences in first-generation and traditional college students' understandings of faculty expectations. Higher Education, 55(4), 425-446.

Dweck, C. S. (2007). The secret to raising smart kids. Scientific American, 18(6), 36-43.

Estrella, K. (2005). Expressive therapy: An integrated arts approach. Expressive therapies, 183-209.

Graunke, S. S., \& Woosley, S. A. (2005). An Exploration of the Factors that Affect the Academic Success of College Sophomores. College Student Journal, 39(2).

Hansen, J. G., \& Liu, J. (2005). Guiding principles for effective peer response. ELT journal, 59(1), 31-38.

Hayes, B. G. (2008). The use of multimedia instruction in counselor education: A creative teaching strategy. Journal of Creativity in Mental Health, 3(3), 243-253.

Ishaq, I. (2006). Pendidikan sebagai investasi masa depan: Yayasan Obor Indonesia.

Jacobs, E. (2011). Impact Therapy (paper presented in the Seminar and Workshop at UPI Bandung On 29 and 30 October 2011).

Jacobs, E. E., Masson, R. L., Harvill, R. L., \& Schimmel, C. J. (2011). Group counseling: Strategies and skills: Cengage learning.

Khotijah, L. N., \& Rahman, I. K. (2017). KONSEP BIMBINGAN KONSELING IMPACT BERBASIS ISLAM UNTUK MENINGKATKAN REGULASI DIRI DALAM PEMANFAATAN GADGET. Jurnal Hisbah, 13(2).

Klorer, P. G. (2005). Expressive therapy with severely maltreated children: Neuroscience contributions. Art therapy, 22(4), 213-220.

Levine, S. (1999). Poiesis and Post-modernism: The search for a foundation in expressive arts therapy. Foundations of expressive arts therapy: Theoretical and clinical perspectives, 19-36.

Malchiodi, C. A. (2012). Art therapy and health care: Guilford Press.

Malchiodi, C. A. (2013). Expressive therapies: Guilford Publications.

Malchiodi, C. A. (2014). Creative arts therapy approaches to attachment issues. Creative arts and play therapy for attachment problems, 3-18.

McAuliffe, G., \& Eriksen, K. (2000). Preparing Counselors and Therapists: Creating Constructivist and Developmental Programs: ERIC.

McNiff, S. (2008). Art-based research. Handbook of the arts in qualitative research, 29-40.

Molina, B., Monteiro-Leitner, J., Garrett, M. T., \& Gladding, S. T. (2005). Making the connection interweaving multicultural creative arts through the power of group counseling interventions. Journal of Creativity in Mental Health, 1(2), 5-15.

Norcross, J. C., Krebs, P. M., \& Prochaska, J. O. (2011). Stages of change. Journal of clinical psychology, 67(2), 143-154.

Rubin, J. A. (2016). Approaches to art therapy: Theory and technique: Routledge.

Sarafino, E. (2006). FBMUI 1TZDIPMPHZ CJPQTZDIP-social interactions: New York: Wiley.

Stiggins, R. J., Arter, J. A., Chappuis, J., \& Chappuis, S. (2004). Classroom assessment for student learning: doing it right--using it well: Assessment Training Institute.

Swales, J. M., \& Feak, C. B. (2004). Academic writing for graduate students: Essential tasks and skills (Vol. 1): University of Michigan Press Ann Arbor, MI.

Triyono. (2016 ). Application of Creative Techniques in Counseling Reality to Solve Problems School Refusal Students. . The paper in the Proceedings of the National Seminar on Guidance and Counseling.

Wiener, D. J. (1999). Beyond talk therapy: Using movement and expressive techniques in clinical practice: American Psychological Association.

Wubbolding, R. E. (2013). Reality therapy for the 21st century: Routledge. 